\title{
Manejo químico de Urochloa ruziziensis consorciado com soja na savana de Roraima
}

\author{
Chemical management of Urochloa ruziziensis intercropping in soybean \\ crop in savanah of Roraima
}

Guilherme Silva Rodrigues ${ }^{1}$, Roberto Dantas de Medeiros ${ }^{2}$, José Anchieta Alves Albuquerque ${ }^{3 *}$, Oscar José Smiderle ${ }^{2}$, José Maria Arcanjo Alves ${ }^{3}$, Antonio Alberto da Silva ${ }^{4}$

Resumo - O objetivo do estudo foi avaliar o manejo químico de Urochloa ruziziensis consorciado com soja em sistema de plantio direto na savana de Roraima. O experimento foi conduzido em campo, em área experimental localizada no município de Boa Vista - RR, no ano de 2015. Os tratamentos consistiram da combinação de quatro doses do herbicida glyphosate $\left(720 ; 1.200 ; 1.680\right.$ e $2.160 \mathrm{~g} \mathrm{ha}^{-1}$ de i.a) pulverizado antes da semeadura da soja como dessecante e cinco doses do herbicida fenoxaprop-p-ethyl ( $0 ; 38,5$; 77; 115,5 e $154 \mathrm{~g} \mathrm{ha}^{-1}$ de i.a.) pulverizado 32 dias após a emergência da cultura em pós-emergência. O delineamento experimental foi o de blocos completos casualizados no esquema de parcelas subdivididas, com quatro repetições. Para a cultura da soja foram avaliados a altura de plantas, altura de inserção da $1^{\text {a }}$ vagem, número de vagens por planta, número de grãos por vagem, massa de 100 grãos e produtividade de grãos em $\mathrm{kg} \mathrm{ha}^{-1}$. Para a U. ruziziensis foram avaliadas a massa de forragem fresca e seca aos 70 dias após a colheita da soja e expressa em $\mathrm{kg} \mathrm{ha}^{-1}$. Conclui-se que, para as condições do cerrado de Roraima, apenas a aplicação do glyphosate na dose de $1.387,64 \mathrm{~g} \mathrm{ha}^{-1}$ aplicado em pós-emergência na cultura da soja, garante máxima produtividade de grãos $\left(3.660,07 \mathrm{~kg} \mathrm{ha}^{-1}\right)$ e de massa fresca $\left(10.136,22 \mathrm{~kg} \mathrm{ha}^{-1}\right)$ e seca $\left(2.404,63 \mathrm{~kg} \mathrm{ha}^{-1}\right)$ de $U$. ruziziensis para formação de cobertura do solo para o próximo plantio, necessário para garantir a sustentabilidade do sistema produtivo.

Palavras-chave: cobertura vegetal, componentes de produção, dessecação, forrageiras

Abstract - The objective of the study was to evaluate the chemical management of Urochloa ruziziensis intercropped with soybean under no tillage system in the Roraima savanna. The experiment was conducted in an experimental area located in the municipality of Boa Vista - RR, in the year 2015. The treatments consisted of the combination of four doses of the herbicide glyphosate $(720 ; 1.200$; 1.680 and $2.160 \mathrm{~g} \mathrm{ha}^{-1}$ of i.a) sprayed prior to sowing the soybean as a desiccant and five doses of the herbicide fenoxaprop-p-ethyl $\left(0 ; 38.5 ; 77 ; 115.5\right.$ and $154 \mathrm{~g} \mathrm{ha}^{-1}$ of i.a) sprayed 32 days after emergence of the post-emergence crop. The experimental design was a randomized complete block in the subdivided plots scheme, with four replications. For the soybean crop were evaluated the height of plants, height of insertion of the first pod, number of pods per plant, number of grains per pod, mass of

Recebido: Outubro 01, 2017. Aceito: Julho 17, 2018.

${ }^{1}$ Agência de Defesa Agropecuária - ADERR, Boa Vista, RR, Brasil. E-mail: guilhermesr.agro@gmail.com

${ }^{2}$ Empresa Brasileira de Pesquisa Agropecuária - EMBRAPA, Boa Vista, RR, Brasil.

E-mail: roberto.medeiros@embrapa.br; oscar.smiderle@embrapa.br

${ }^{3}$ Programa de Pós-graduação em Agronomia - POSAGRO, Universidade Federal de Roraima - UFRR, Campus Cauamé, BR 174, KM 12, Monte Cristo, CEP 69300-000, Boa Vista, RR, Brasil. E-mail: aanchietaufrr@gmail.com; arcanjo.alves@ufrr.br

${ }^{4}$ Programa de Pós-graduação em Fitotecnia - POSFITOTECNIA, Universidade Federal de Viçosa - UFV, Viçosa, MG, Brasil. E-mail: aasilvapd@gmail.com 
100 grains and grain yield in $\mathrm{kg} \mathrm{ha}^{-1}$. The fresh and dry forage mass was evaluated for U. ruziziensis at 70 days after soybean harvest and expressed in $\mathrm{kg} \mathrm{ha}^{-1}$. It was concluded that only the application of glyphosate at a dose of 1387,64 $\mathrm{g} \mathrm{ha}^{-1}$, applied in post-emergence in the soybean crop, guarantees maximum grain yield (3660,07 $\left.\mathrm{kg} \mathrm{ha}^{-1}\right)$ and of fresh mass $\left(10136,22 \mathrm{~kg} \mathrm{ha}^{-1}\right)$ and dry matter $(2404,63$ $\mathrm{kg} \mathrm{ha}^{-1}$ ) of $U$. ruziziensis for soil cover for the next planting, necessary to guarantee the sustainability of the productive system.

Keywords: cover crops, production components, desiccation, forage

\section{Introdução}

O cultivo da soja apresenta-se como uma das atividades agrícolas de grande potencial para as áreas de cerrado em Roraima, tem-se identificado promissor potencial agrícola da soja para a região, alta insolação pela proximidade da linha do Equador, o que se reflete em qualidade dos grãos produzidos e a época de colheita na entressafra do Centro-Sul, possibilitando obter preços mais competitivos (Zilli et al., 2007).

O sistema de plantio direto (SPD) com uso de plantas de cobertura do solo representa opção favorável para minimizar os impactos no uso intensivo do solo e melhorar as propriedades químicas, físicas e biológicas do solo (Carvalho et al., 2011a, 2011b; Silva et al., 2014). Norsworthy et al. (2012) citam que é fundamental contemplar ao uso dos herbicidas, preservando a eficácia de controle pela rotação de mecanismos de ação e prevenção da seleção de biótipos resistentes, sendo o glyphosate o mais utilizado (Timossi et al., 2016; Nonemacher et al., 2017).

De acordo com Correia (2017) a integração entre lavoura e pecuária é a forma que os produtores encontraram para mudar a base da economia de Roraima. Após a colheita da soja, muitos produtores do Estado reutilizam o solo para o plantio de capim com finalidade de engorda do gado. A adoção de espécies do gênero Brachiaria vem sendo recomendada como planta de cobertura pela excelente adaptação a solos de baixa fertilidade, fácil estabelecimento e considerável produção de biomassa durante o ano, proporcionando excelente cobertura vegetal do solo (Timossi et al., 2007; Machado e Assis,
2010; Adegas et al., 2011; Costa et al., 2013; Albuquerque et al., 2017).

Medeiros et al. (2009) citam que uma das dificuldades de se utilizar o sistema de plantio direto em Roraima é o reduzido conhecimento de espécies de plantas para a cobertura do solo após a colheita das culturas comerciais, devido ao longo período de déficit hídrico anual. Uma das alternativas para as regiões com as condições edafoclimáticas do cerrado é a utilização de espécies de plantas forrageiras do gênero Urochloa, uma vez que produzem biomassa satisfatoriamente para a prática do plantio direto, fornecendo forragem para sistema lavoura-pecuária e inibindo a incidência das plantas daninhas (Ferreira et al., 2010; Lima et al., 2014).

A Braquiária é uma espécie forrageira bastante utilizada pelos produtores de grãos no sistema-integração-lavoura-pecuária, entretanto são poucas as informações sobre o manejo desta espécie sobre intensidade de pastejo e efeitos na cultura da soja em sucessão (Ferreira et al., 2015; Franchini et al., 2015a, 2015b; Balbinot Junior et al., 2016).

Uma alternativa que vem sendo recomendada é a condução simultânea da espécie anual com a planta de cobertura, sendo esta manejada com o uso de doses reduzidas de herbicidas. Para que o consórcio seja viável, é necessário o correto manejo da forrageira minimizando-se a competição com a cultura, o que possibilita aumento de produtividade da cultura e de biomassa da braquiária (Carvalho et al., 2011a; Silva et al., 2014). 
O objetivo do estudo foi avaliar o manejo químico de Urochloa ruziziensis consorciado com soja em sistema de plantio direto na savana de Roraima.

\section{Material e métodos}

O experimento foi conduzido em campo, em área experimental localizada no município de Boa Vista - RR, cujas coordenadas são $\left(02^{\circ} 49^{\prime} 11^{\prime \prime} \mathrm{N}\right.$ e $60^{\circ} 40^{\prime} 24^{\prime \prime} \mathrm{W}$ e $85 \mathrm{~m}$ de altitude), no período de maio a novembro de 2015 . O clima da região segundo a classificação de köppen é do tipo Aw, tropical chuvoso, com precipitação média anual de aproximadamente $1.600 \mathrm{~mm}$ e umidade relativa do ar em torno de $70 \%$ (Araújo et al.,
2001). O experimento foi instalado em uma área estabelecida com a espécie forrageira U. ruziziensis desde o ano de 2010. O solo da área experimental é classificado como LATOSSOLO AMARELO, cujos resultados das análises química e granulométrica encontram-se na Tabela 1. Os dados referentes à temperatura e precipitação pluviométrica foram obtidos na Fundação Estadual de Meio Ambiente e Recursos Hídricos (Figura 1).

Antes de instalar o experimento roçou a braquiária e observou-se que a massa seca da forragem total da área experimental foi de $6.378 \mathrm{~kg} \mathrm{ha}^{-1}$.

Os tratamentos consistiram da combinação de quatro doses do herbicida glyphosate

Tabela 1. Análise granulométrica e química do solo nas camadas 0-20 e 20-40 cm da área experimental sobre pastagem de U. ruziziensis, no cerrado de Roraima. Boa Vista, RR, 2016.

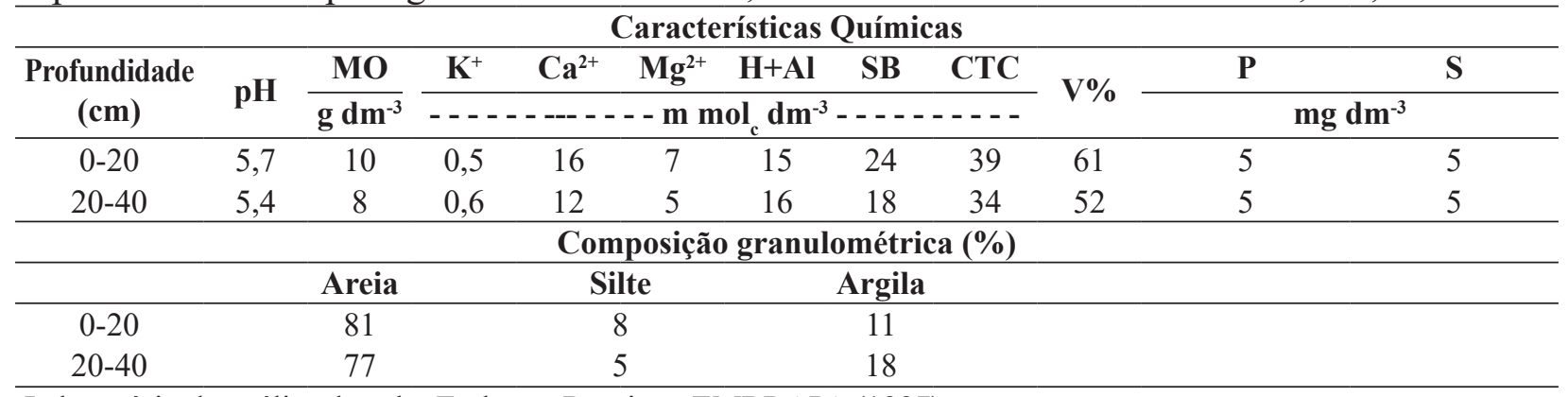

Laboratório de análise de solo, Embrapa Roraima. EMBRAPA (1997).

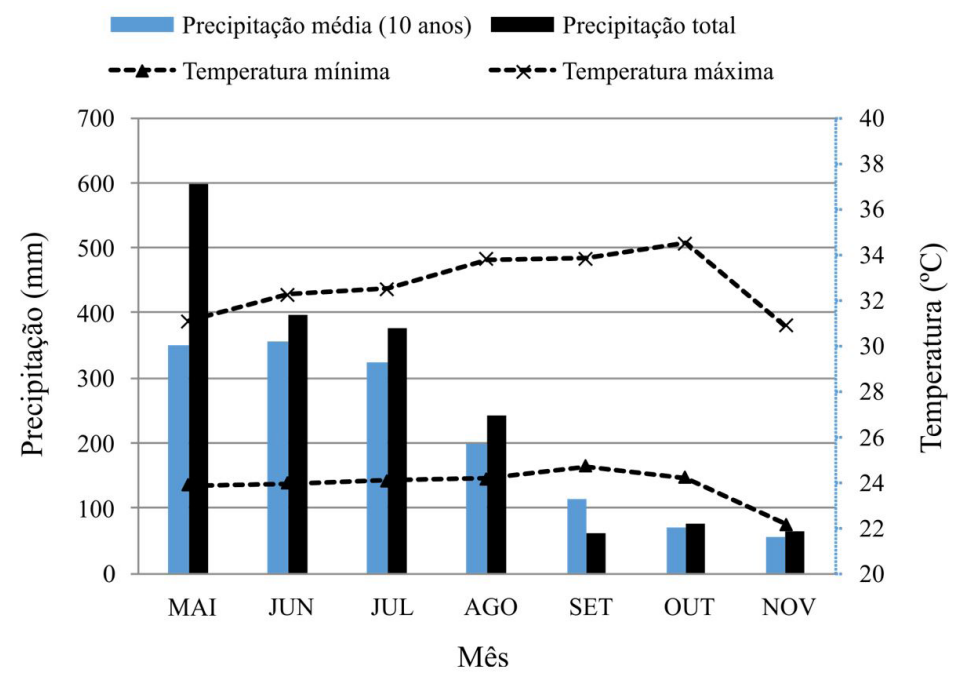

Figura 1. Precipitação pluvial média (dez anos), precipitação total (mm) e médias mensais de temperatura $\left({ }^{\circ} \mathrm{C}\right)$ máxima e mínima, observadas durante a condução do experimento. 
(720, 1.200, 1.680, e $2.160 \mathrm{~g} \mathrm{ha}^{-1}$ de i.a) pulverizado antes da semeadura da soja como dessecante e cinco doses do herbicida fenoxaprop-p-ethyl $\left(0,38,5,77,115,5,154 \mathrm{~g} \mathrm{ha}^{-1}\right.$ de i.a. $)$ pulverizado em pós-emergência na cultura da soja. O delineamento experimental foi o de blocos completos casualizados no esquema de parcelas subdivididas, com quatro repetições. As parcelas (doses de glyphosate) apresentaram 108,0 $\mathrm{m}^{2}(18,0 \mathrm{~m} \times 6,0 \mathrm{~m}) \mathrm{de}$ área total, espaçadas entre si em 2,5 m, e as subparcelas (doses de fenoxaprop-p-ethyl) 21,6 $\mathrm{m}^{2}(3,60 \mathrm{~m} \times 6,0 \mathrm{~m})$ de área total, com área útil de $9,0 \mathrm{~m}^{2}(1,80 \mathrm{~m} \times 5,0 \mathrm{~m})$.

$\mathrm{Na}$ primeira quinzena do mês de fevereiro, as plantas de braquiária da área experimental foram roçadas devido ao porte elevado em que se encontravam, o que poderia prejudicar a eficácia dos tratamentos utilizados na dessecação.

O glyphosate, nas diferentes doses, foi aplicado em 4/5/2015, utilizando-se pulverizador tratorizado com barra de pulverização de $6,5 \mathrm{~m}$, com 13 pontas tipo jato em leque azul TFA/10 03, espaçados em $0,50 \mathrm{~m}$ entre si. A velocidade de aplicação foi de $6 \mathrm{~km} \mathrm{~h}^{-1}$, a pressão de $40 \mathrm{lbf} \mathrm{pol}^{-2}$, com volume de calda de $270 \mathrm{~L} \mathrm{ha}^{-1}$.

A soja foi semeada 15 dias após a dessecação. Procedeu-se a semeadura da cultivar de soja BRS Tracajá, que é a mais cultivada pelos produtores no Estado. As sementes foram inoculadas no dia do plantio com Bradyrhizobium japonicum. Utilizou-se semeadora-adubadora própria para plantio direto, em linhas espaçadas de 0,60 m com densidade de semeadura de 16 sementes por metro linear. A adubação de semeadura foi realizada com $350 \mathrm{~kg}$ $\mathrm{ha}^{-1}$ de um formulado comercial correspondendo a $7 \mathrm{~kg} \mathrm{ha}^{-1}$ de N, $98 \mathrm{~kg} \mathrm{ha}^{-1}$ de $_{2} \mathrm{O}_{5}$ e $56 \mathrm{~kg} \mathrm{ha}^{-1} \mathrm{de}_{2} \mathrm{O}$. A adubação em cobertura foi realizada aos 35 dias após a emergência (DAE) com $70 \mathrm{~kg} \mathrm{ha}^{-1} \mathrm{de}_{2} \mathrm{O}$ na forma de cloreto de potássio.

O herbicida fenoxaprop-p-ethyl foi aplicado aos 32 DAE da soja, não tendo sido realizado antes devido às condições de chuva que impediam a pulverização. Utilizou-se pulverizador costal pressurizado com $\mathrm{CO}_{2}$, a pressão constante de $25 \mathrm{lbf} \mathrm{pol}^{-2}$ equipado com barra de pulverização de 2,0 m, munida de cinco pontas de pulverização de jato plano 8003 , espaçadas em $0,5 \mathrm{~m}$ entre si, com consumo de $250 \mathrm{~L} \mathrm{ha}^{-1}$ de calda.

No dia seguinte à aplicação das doses de fenoxaprop-p-ethyl, toda a área experimental foi pulverizada com herbicida latifolicida (fomesafen $250 \mathrm{~g} \mathrm{ha}^{-1}$ de i.a.), devido à grande presença de Calopogonio muconoides, Alternanthera tenella e Stylosanthes capitata.

Para a cultura da soja foram avaliados a altura de plantas, determinada pela média de 10 plantas colhidas ao acaso no dia anterior a colheita; altura de inserção da $1^{\mathrm{a}}$ vagem, determinada nas mesmas 10 plantas onde se avaliou a altura, medidas da base de cada planta até a primeira vagem; número de vagens por planta, determinada pela média de 5 plantas colhidas ao acaso; número de grãos por vagem, obtido após debulha manual das vagens de 5 plantas, sendo determinada pela relação entre número de grãos e de vagens; massa de 100 grãos, determinada pela média de quatro amostras de 100 grãos obtidas após a colheita das plantas da área útil da unidade experimental; e produtividade de grãos corrigida para 13\% de umidade e expressa em $\mathrm{kg} \mathrm{ha}^{-1}$, obtida através da colheita de todas as plantas da área útil. Para a U. ruziziensis foram avaliadas a massa de forragem fresca e seca aos 70 dias após a colheita da soja, mediante a coleta de duas amostras de $0,25 \mathrm{~m}^{2}$ cortadas rente ao solo, sendo expressa em $\mathrm{kg} \mathrm{ha}^{-1}$. Amostras frescas da forragem foram submetidas a secagem em estufa ( $65^{\circ} \mathrm{C}$ por 72 horas) para determinação da massa de forragem seca e convertida em $\mathrm{kg} \mathrm{ha}^{-1}$.

Os resultados foram submetidos à análise de variância com aplicação do teste $F(p<0,05)$. As variáveis massa fresca e massa seca de U. ruziziensis foram transformadas em $\sqrt{x+0,5}$ para análise dos dados. Realizou-se análise de regressão na presença de efeito significativo para as doses de glyphosate e fenoxaprop-p-ethyl. 


\section{Resultados e discussão}

Não se detectou efeito significativo $(p<0,05)$ das doses de fenoxaprop-p-ethyl e da interação entre as doses de glyphosate e fenoxaprop-p-ethyl em nenhuma variável avaliada na cultura da soja (Tabela 2).

As doses de glyphosate influenciaram significativamente no número de vagens por planta, no número de grãos por vagem e na produtividade de grãos. Porém, a massa de cem grãos, a altura de plantas e de inserção da primeira vagem não foram afetadas por esse herbicida (Tabela 2).

As médias obtidas para os componentes de produção da soja em função das doses de glyphosate e de fenoxaprop-p-ethyl são apresentadas na Tabela 3.

Tabela 2. Quadrados médios e médias de altura de plantas (ALT), altura da inserção da $1^{\mathrm{a}}$ vagem (AIV), número de vagens por planta (NVP), número de grãos por vagem (NGV), massa de 100 grãos (M100G) e produtividade (PROD) de soja BRS Tracajá em função das doses de glyphosate e fenoxaprop-p-ethyl. Boa Vista-RR, 2016.

\begin{tabular}{|c|c|c|c|c|c|c|}
\hline \multirow[b]{2}{*}{$\begin{array}{l}\text { Fonte de } \\
\text { Variação }\end{array}$} & \multicolumn{6}{|c|}{ Quadrados Médios } \\
\hline & ALT (cm) & $\operatorname{AIV}(\mathrm{cm})$ & NVP & NGV & $\begin{array}{c}\text { M100G } \\
\text { (g) }\end{array}$ & $\begin{array}{c}\text { PROD } \\
\left(\mathrm{kg} \mathrm{ha}^{-1}\right)\end{array}$ \\
\hline Bloco & $7,13^{\text {ns }}$ & $2,4^{\mathrm{ns}}$ & $660,15 * *$ & $0,0045^{\mathrm{ns}}$ & $1,08^{\mathrm{ns}}$ & $3780826,91 * *$ \\
\hline Glyphosate (G) & $3,25^{\mathrm{ns}}$ & $4,6^{\mathrm{ns}}$ & $310,44^{*}$ & $0,0125^{*}$ & $0,68^{\mathrm{ns}}$ & $2050511,96^{*}$ \\
\hline Erro A & 6,49 & 2,31 & 58,22 & 0,0019 & 0,89 & 422235 \\
\hline Fenoxaprop-p-ethyl (F) & $4,95^{\mathrm{ns}}$ & $3,33^{\text {ns }}$ & $13,86^{\mathrm{ns}}$ & $0,0018^{\mathrm{ns}}$ & $1,22^{\mathrm{ns}}$ & $83217,70^{\text {ns }}$ \\
\hline $\mathrm{G}^{*} \mathrm{~F}$ & $3,61^{\mathrm{ns}}$ & $1,70^{\mathrm{ns}}$ & $29,94^{\mathrm{ns}}$ & $0,0022^{\mathrm{ns}}$ & $0,46^{\mathrm{ns}}$ & $171042,94^{\mathrm{ns}}$ \\
\hline Erro B & 9,78 & 1,37 & 35,72 & 0,0024 & 0,65 & 202320,49 \\
\hline Média & 52,82 & 17,01 & 49,37 & 2,43 & 13,74 & 3321,97 \\
\hline C.V. (G) $\%$ & 4,83 & 8,95 & 15,45 & 1,81 & 6,89 & 19,56 \\
\hline C.V. (F) $\%$ & 5,93 & 6,89 & 12,10 & 2,01 & 5,91 & 13,54 \\
\hline
\end{tabular}

ns, $*, * *=$ não significativo, significativo a $5 \%$ e $1 \%$, respectivamente, pelo teste $\mathrm{F}$; C.V. $=$ Coeficiente de variação.

Tabela 3. Médias de altura de plantas (ALT), altura da inserção da $1^{\text {a }}$ vagem (AIV), número de vagens por planta (NVP), número de grãos por vagem (NGV), massa de 100 grãos (M100G) e produtividade (PROD) de soja BRS Tracajá em função das doses de glyphosate e fenoxaprop-p-ethyl. Boa Vista-RR, 2016.

\begin{tabular}{ccccccc}
\hline Tratamentos & ALT (cm) & AIV (cm) & NVP & NGV & $\begin{array}{c}\text { M100G } \\
(\mathbf{g})\end{array}$ & $\begin{array}{c}\text { PROD } \\
\left.\mathbf{( k g ~ h a}^{-1}\right)\end{array}$ \\
\hline Glyphosate (G) & & & & & & \\
720 & 52,49 & 16,67 & 47,64 & 2,40 & 13,51 & $3.152,15$ \\
1.200 & 52,64 & 16,80 & 52,23 & 2,45 & 13,68 & $3.586,47$ \\
1.680 & 52,75 & 16,85 & 52,98 & 2,45 & 13,82 & $3.594,24$ \\
2.160 & 53,41 & 17,72 & 44,64 & 2,44 & 13,94 & $2.955,03$ \\
Fenoxaprop-p-ethyl (F) & & & & & & \\
0 & 53,30 & 16,75 & 48,63 & 2,43 & 13,44 & $3.207,17$ \\
38,5 & 53,11 & 16,77 & 49,96 & 2,44 & 13,56 & $3.330,54$ \\
77,0 & 53,26 & 16,65 & 50,67 & 2,45 & 13,67 & $3.407,57$ \\
115,5 & 52,30 & 17,76 & 49,13 & 2,43 & 13,92 & $3.330,03$ \\
154,0 & 52,14 & 17,11 & 48,46 & 2,42 & 14,12 & $3.334,56$ \\
Média geral & 52,82 & 17,01 & 49,37 & 2,43 & 13,74 & $3.321,97$ \\
C.V. (G) \% & 4,83 & 8,95 & 15,45 & 1,81 & 6,89 & 19,56 \\
C.V. (F) \% & 5,93 & 6,89 & 12,10 & 2,01 & 5,91 & 13,54 \\
\hline
\end{tabular}

C.V. $=$ Coeficiente de variação. 
O número de vagens por planta teve acréscimo até a dose de $1.381,85 \mathrm{~g} \mathrm{ha}^{-1}$ de glyphosate, com 53,39 vagens por plantas. O mesmo ocorreu para o número de grãos por vagem até a dose de 1.632,35 $\mathrm{g} \mathrm{ha}^{-1}$, obtendo-se 2,46 grãos por vagem (Figura 2). A produtividade apresentou comportamento semelhante, se ajustando a um modelo de regressão quadrático, com a máxima eficiência técnica sendo obtida na dose $1.387,64 \mathrm{~g} \mathrm{ha}^{-1}$ de glyphosate (Figura 3), com 3.660,36 kg ha-1.

A competição exercida pela braquiária quando se utilizou a menor dose de glyphosate na dessecação não influenciou as características número de vagens por planta e o número de grãos por vagem. Segundo Alves et al. (2013), o componente de produção da soja mais influenciado pela competição, em sistemas consorciados, é o número de vagens por planta.

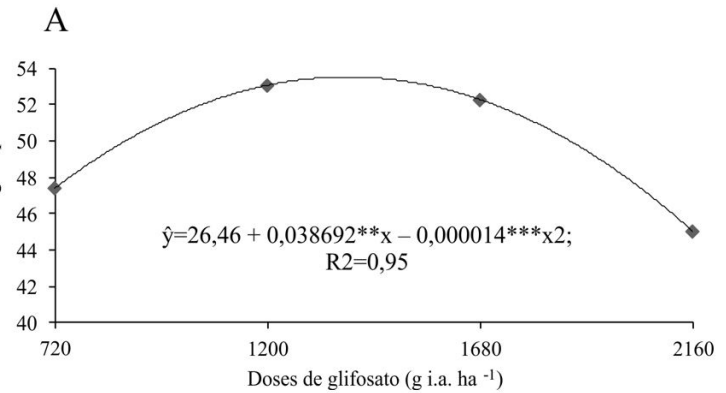

O aumento das doses de glyphosate até $1.387 \mathrm{~g} \mathrm{ha}^{-1}$ promoveu aumento na produtividade até $3.660 \mathrm{~kg} \mathrm{ha}^{-1}$, devido à redução da competição exercida pelas plantas de braquiária sobreviventes, 0 que favoreceu ao bom rendimento dos componentes de produção, número de vagens por planta e número de grãos por vagem, que são uns dos principais componentes do rendimento em soja. As doses mais elevadas de glyphosate foram prejudiciais à produtividade, devido à redução no número de vagens por planta e de grãos por vagem.

O aumento gradativo das doses de glyphosate proporcionou maior controle da forrageira, reduzindo o número de plantas que se mantiveram vivas ou que rebrotaram após a dessecação. No entanto, doses mais elevadas de glyphosate também foram prejudiciais aos componentes de produção e produtividade. Segundo Coupland e

Figura 2. Número de vagens por planta (A) e número de grãos por vagem (B) de soja BRS Tracajá, em função das doses do herbicida glyphosate, pulverizado antes da instalação da cultura, na dessecação de U. ruziziensis. Boa Vista, RR. 2016.

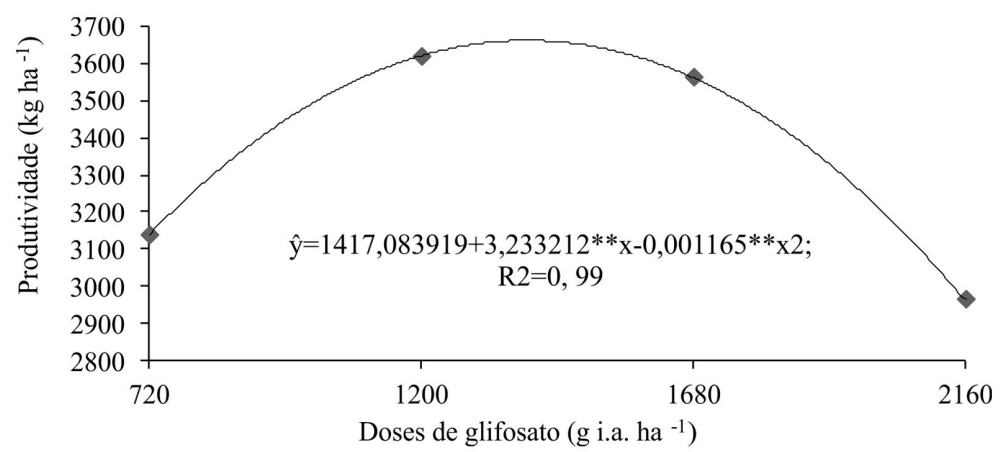

Figura 3. Produtividade de grãos de soja BRS Tracajá em função de doses de herbicida glyphosate na dessecação de U. ruziziensis no cerrado de Roraima. Boa Vista-RR, 2016. 
Lutman (1982), existe a possibilidade de exsudação radicular de herbicidas das plantas daninhas para a cultura cultivada em decorrência da aplicação de doses elevadas de herbicidas, como uma resposta ao menor desenvolvimento de plantas cultivadas, principalmente se as raízes da cultura estiverem muito numerosas e próximas às raízes das plantas daninhas tratadas com o herbicida.

Diversas doses de glyphosate têm sido testadas para o controle de plantas de cobertura. A sua dose correta na dessecação de plantas de cobertura pode variar de acordo com a espécie e estádio de desenvolvimento, conforme constatações de Timossi et al. (2007), trabalhando com as espécies Brachiaria brizantha, Brachiaria decumbens e Pennisetum glaucum, e Nepomuceno et al. (2012) com a espécie Urochloa rhuziziensis. Silva et al. (2013) avaliaram quatro doses de glyphosate em três espécies do gênero Urochloa (U. ruziziensis, $U$. decumbens e $U$. brizantha), a maior eficácia do herbicida ocorreu na $U$. ruziziensis.

Oliveira Júnior et al. (2010) também não verificaram diferença significativa para a produtividade de grãos de soja com a utilização de doses reduzidas do herbicida haloxyfop-methyl em pós-emergência no consórcio da soja com B. brizantha. Apesar da interação para os componentes de produção e produtividade de soja não ter sido significativa, a dose de $720 \mathrm{~g} \mathrm{ha}^{-1}$ de glyphosate combinada com a ausência do herbicida fenoxaprop-p-ethyl foi

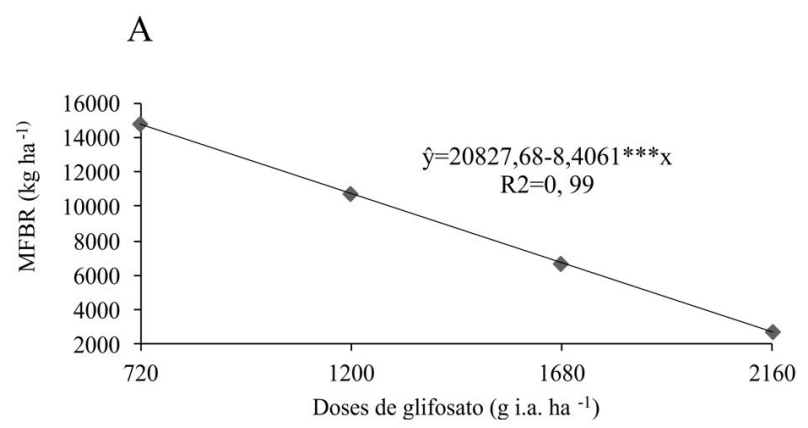

prejudicial a colheita da cultura, devido à altura das plantas de braquiária e a presença de plantas daninhas que ocasionaram maior dificuldade de colheita, visto que a dessecação foi pouco eficaz no controle destas. Como não houve o controle destas em pós-emergência na dose zero de fenoxaprop-p-ethyl, estas apresentaram maior desenvolvimento, o que comprometeu a colheita da soja.

Desse modo, a dose de fenoxaprop-p-ethyl que permitiu viabilidade técnica das operações de colheita, de modo a reduzir os custos e minimizar os impactos dos herbicidas na cultura, foi de 38,5 $\mathrm{g} \mathrm{ha}^{-1}$, que favoreceu boa condução da forrageira sem prejuízo à produtividade da soja.

Quanto à produtividade da parte aérea de U. ruziziensis obtida aos 70 dias após a colheita da soja, houve efeito significativo para as doses de glyphosate e fenoxaprop-p-ethyl nas variáveis avaliadas, mas a interação dos mesmos não foi significativa.

A massa fresca e seca das plantas de braquiária se ajustaram a um modelo de regressão linear, com declínio da produção com o aumento das doses de glyphosate nas proporções de 8,46 e 1,77 kg ha-1 de massa fresca e seca, respectivamente, para cada grama de glyphosate aplicado na dessecação (Figura 4).

As doses de glyphosate 720 e $1.200 \mathrm{~g} \mathrm{ha}^{-1}$ proporcionaram as maiores produções de massa

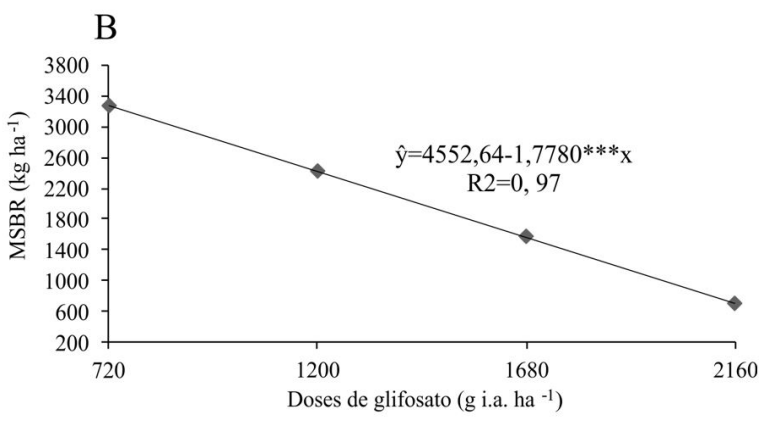

Figura 4. Massa fresca - MFUR (A) e seca-MSUR (B) de U. ruziziensis aos 70 dias após a colheita da soja, em função de doses do herbicida glyphosate pulverizado antes da instalação da cultura, na dessecação da forrageira. Boa Vista-RR, 2016. 
verde, com valores acima de $10.740 \mathrm{~kg} \mathrm{ha}^{-1}$ (Figura 4A), o que confere a estes tratamentos a possibilidade de pastejo aos 70 dias após a colheita da soja. A precipitação total após a colheita da soja até os $70 \mathrm{DAE}$ foi de 204,3 mm, que, embora não seja a mais adequada, contribuiu com o desenvolvimento da braquiária que já ocorria em função da desfolha da soja observada alguns dias antes da colheita.

Apenas a dose de $720 \mathrm{~g} \mathrm{ha}^{-1}$ de glyphosate proporcionou massa seca superior a $3.000 \mathrm{~kg} \mathrm{ha}^{-1}$ (Figura 4B), valor este que pode ser considerado baixo para a produção de palhada para cobertura do solo. No entanto, nas condições edafoclimáticas do cerrado de Roraima, onde há dificuldade de se estabelecer cobertura do solo para o período entressafra, estes valores tendem a apresentar aumento até o plantio na safra seguinte, chegando próximo ao valor adequado, corroborando com Medeiros et al. (2009), que obtiveram aumento da massa seca de $U$. ruziziensis semeada em diferentes épocas no cerrado de Roraima.

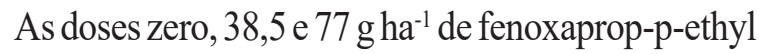
proporcionaram quantidade de massa fresca adequada ao consumo animal, com produção total acima de $8.000 \mathrm{~kg} \mathrm{ha}^{-1}$ (Figura 5A). Em relação à massa seca, todas as doses de fenoxaprop-p-ethyl proporcionaram produção inferior a $3.000 \mathrm{~kg} \mathrm{ha}^{-1}$ (Figura 5B).

Silva et al. (2005) observaram redução da taxa de crescimento absoluto de B. brizantha, demonstrando a possibilidade da utilização de doses reduzidas de fluazifop-p-butyl na redução do crescimento da braquiária sem, contudo, causar danos letais à forrageira. Estes autores avaliando ainda o efeito de doses de fluazifop-p-butyl em pós-emergência no consórcio soja e $B$. brizantha, verificaram efeito do graminicida no acúmulo de massa seca de forrageira por ocasião da colheita da soja, havendo queda acentuada da massa em função do aumento das doses do graminicida a partir da dose de $30 \mathrm{~g} \mathrm{ha}^{-1}$, com produção de massa seca inferior a $1 \mathrm{t} \mathrm{ha}^{-1}$.

Os resultados obtidos para a produção de soja sobre cobertura com U. ruziziensis com base no uso de herbicidas evidenciaram que a dose de $1.387 \mathrm{~g} \mathrm{ha}^{-1}$ de glyphosate pulverizado antes da instalação da cultura, em dessecação, foi adequada, pois permitiu produção satisfatória de grãos (Figura 3) e acúmulo pela forrageira de $9.171 \mathrm{~kg} \mathrm{ha}^{-1}$ de massa fresca (Figura 4A), quantidade satisfatória para o pastejo aos 70 dias após a colheita.

O acúmulo de massa fresca e seca de U. ruziziensis, aos 70 dias após a colheita da soja, diminuiu com o aumento das doses de glyphosate (Figuras 4A, B), pulverizado antes da instalação da cultura em dessecação, e de fenoxaprop-p-ethyl, pulverizado em pós-emergência na soja.

O número de vagens por planta, o número de grãos por vagem e a produtividade de grãos apresentaram acréscimo até as doses de
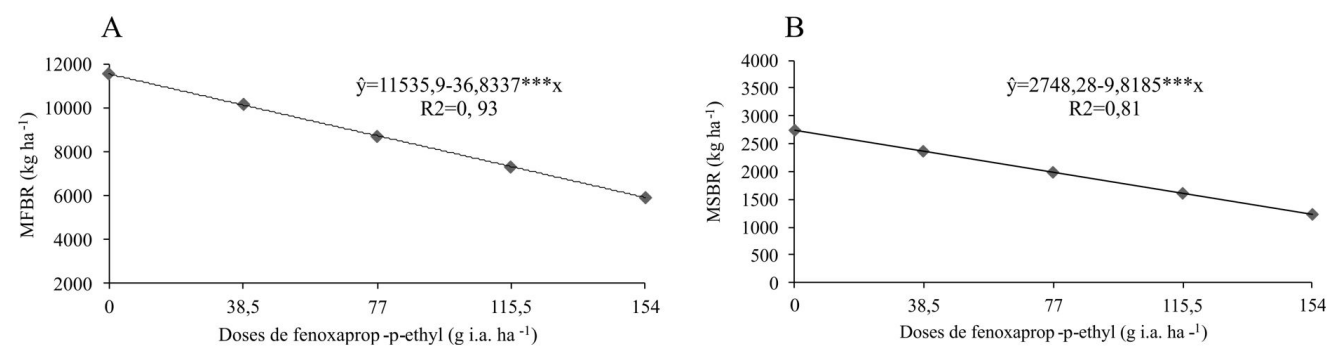

Figura 5. Massa fresca-MFUR (A) e seca-MSUR (B) de U. ruziziensis aos 70 dias após a colheita da soja, em função de doses do herbicida fenoxaprop-p-ethyl pulverizado em pós-emergência na cultura da soja. Boa Vista-RR, 2016. 
$1.381,85,1.632,35$ e $1.387 \mathrm{~g} \mathrm{ha}^{-1}$ de glyphosate, respectivamente, obtendo-se 53,39 vagens por planta, 2,46 grãos por vagem e alcançando produtividade de $3.600 \mathrm{~kg} \mathrm{ha}^{-1}$ (Figuras $2 \mathrm{e} 3$ ).

\section{Conclusão}

Para as condições da savana de Roraima, apenas a aplicação do glyphosate na dose de $1.387,64 \mathrm{~g} \mathrm{ha}^{-1}$ aplicado em pós-emergência na cultura da soja, garante máxima produtividade de grãos (3.660.07 $\left.\mathrm{kg} \mathrm{ha}^{-1}\right)$ e de massa fresca $\left(10.136,22 \mathrm{~kg} \mathrm{ha}^{-1}\right)$ e seca $\left(2.404,63 \mathrm{~kg} \mathrm{ha}^{-1}\right) \mathrm{de}$ U. ruziziensis para formação de cobertura do solo para o próximo plantio, necessário para garantir a sustentabilidade do sistema produtivo.

\section{Referências}

Adegas, F.S.; Voll, E.; Gazziero, D.L.P. Manejo de plantas daninhas em milho safrinha em cultivo solteiro ou consorciado à Brachiaria ruziziensis. Pesquisa Agropecuária Brasileira, v.46, n.10, p.1226-1233, 2011. http://dx.doi.org/10.1590/ S0100-204X2011001000016.

Albuquerque, J.A.A.; Santos, T.S.; Castro, T.S.; Melo, V.F.; Rocha, P.R.R. Weed incidence after soybean harvest in no-till and conventional tillage croprotation systems in Roraima's Cerrado. Planta Daninha, v.35, n.0, p.1-12, 2017. http://dx.doi. org/10.1590/s0100-83582017350100034.

Alves, V.B.; Padilha, N.D.S.; Garcia, R.A.; Ceccon, G. Milho safrinha consorciado com Urochloa ruziziensis e produtividade da soja em sucessão. Revista Brasileira de Milho e Sorgo, v.12, n.3, p.280-292, 2013. http://dx.doi.org/10.18512/19806477/rbms.v12n3p280-292.

Araújo, W.F.; Andrade Júnior, A.S.; Medeiros, R.D.; Sampaio, R.A. Precipitação pluviométrica mensal provável em Boa Vista, Estado de Roraima, Brasil. Revista Brasileira de Engenharia Agrícola e Ambiental, v.5, n.3, p.563-567, 2001. http:// dx.doi.org/10.1590/S1415-43662001000300032.
Balbinot Junior, A.; Cezar Franchini, J.; Debiasi, H. Altura de manejo da pastagem, época de dessecação de Urochloa ruziziensis e adubação nitrogenada na cultura da soja em sistema integração lavoura-pecuária. Revista de Ciências Agroveterinárias, v.15, n.2, p.124-133, 2016. http://dx.doi.org/10.5965/223811711522016124.

Carvalho, A.M.; Souza, L.L.P.; Guimarães Júnior, R.; Alves, P.C.A.C.; Vivaldi, L.J. Cover plants with potential use for crop livestock integrated systems in the Cerrado region. Pesquisa Agropecuária Brasileira, v.46, n.10, p.1200-1205, 2011a. http:// dx.doi.org/10.1590/S0100-204X2011001000012.

Carvalho, F.P.; Byrro, E.C.M.; Silva, D.V.; Santos, J.B.; Cury, J.P. Alocação de matéria seca e capacidade competitiva de cultivares de milho com plantas daninhas. Planta Daninha, v.29, n.2, p.373-382, 2011b. http://dx.doi.org/10.1590/ S0100-83582011000200015.

Correia, L.G. Colheita da soja: Roraima registra maior crescimento proporcional da produção de soja no País. Boa Vista: Folha de Boa Vista, 2017. Disponível em: $<$ http://www.folhabv.com. $\mathrm{br} /$ noticia/Roraima-registra-maior-crescimentoproporcional-da-producao-de-soja-no-Pais/2017>. Acesso em: 15 set. 2017.

Costa, N.V.; Peres, E.J.L.; Ritter, L.; Silva, P.V.; Fey, E. Avaliação do glyphosate e paraquat no manejo da Brachiaria ruziziensis. Revista Brasileira de Herbicidas, v.12, n.1, p.31-38, 2013. http://dx.doi.org/10.7824/rbh.v12i1.179.

Coupland, D.; Lutman, P. Investigations into the movement of glyphosate from treated to adjacent untreated plants. Annals of Applied Biology, v.101, n.2, p.315-321, 1982. http:// dx.doi.org/10.1111/j.1744-7348.1982.tb00827.x.

EMBRAPA - Empresa Brasileira de Pesquisa Agropecuária. Manual de métodos de análise de solo. 2. ed. Rio de Janeiro: EMBRAPA, 1997.

Ferreira, A.C.B.; Lamas, F.M.; Carvalho, M.C.S.; Salton, J.C.; Suassuna, N.D. Produção 
de biomassa por cultivos de cobertura do solo e produtividade do algodoeiro em plantio direto. Pesquisa Agropecuária Brasileira, v.45, n.6, p.546-553, 2010. http://dx.doi.org/10.1590/ S0100-204X2010000600003.

Ferreira, G.A.; Oliveira, P.S.R.; Alves, S.J.; Costa, A.C.T. Soybean productivity under different grazing heights of Brachiaria ruziziensis in an integrated crop-livestock system. Revista Ciência Agronômica, v.46, n.4, p.755-763, 2015. http:// dx.doi.org/10.5935/1806-6690.20150063.

Franchini, J.C.; Balbinot Junior, A.A.; Debiasi, H.; Conte, O. Desempenho da soja em consequência de manejo de pastagem, época de dessecação e adubação nitrogenada. Pesquisa Agropecuária Brasileira, v.50, n.12, p.1131-1138, 2015a. http:// dx.doi.org/10.1590/S0100-204X2015001200002.

Franchini, J.C.; Balbinot Junior, A.A.; Debiasi, H.; Conte, O. Crescimento da soja influenciado pela adubação nitrogenada na cultura, pressão de pastejo e épocas de dessecação de Urochloa ruziziensis. Revista Agro@mbiente Online, v.9, p.129-135, 2015b.

Lima, S.F.; Timossi, P.C.; Almeida, D.P.; Silva, U.R. Palhada de Brachiaria ruziziensis na supressão de plantas daninhas na cultura da soja. Agrarian, v.7, n.26, p.541-551, 2014.

Machado, L.A.Z.; Assis, P.G.G. PRODUÇÃO de palha e forragem por espécies anuais e perenes em sucessão à soja. Pesquisa Agropecuária Brasileira, v.45, n.4, p.971-978, 2010. http:// dx.doi.org/10.1590/S0100-204X2010000400010.

Medeiros, R.D.; Smiderle, O.J.; Mourão Junior, M.; Bendahan, A.B.; Cordeiro, A.C.C.; Costa, N.L.C.Avaliação e recomendação de espécies de plantas para cobertura do solo em Roraima. In: Workshop Integração-Lavoura-Pecuária-Floresta na EMBRAPA, 2009, Brasília. Anais... Brasília: Embrapa Amazônia Oriental, 2009.

Nepomuceno, M.P.; Varela, R.M.; Alves, P.L.C.A.; Martins, J.V.F. Períodos de dessecação de Urochloa ruziziensis e seu reflexo na produtividade da soja RR. Planta Daninha, v.30, n.3, p.557-565, 2012. http:// dx.doi.org/10.1590/S0100-83582012000300011.

Nonemacher, F.; Galon, L.; Santin, C.O.; Forte, C.T.; Fiabane, R.C.; Winter, F.L.; et al. Associação de herbicidas aplicados para o controle de plantas daninhas em soja resistente ao glyphosate. Revista Brasileira de Herbicidas, v.16, n.2, p.142-151, 2017. http://dx.doi.org/10.7824/rbh.v16i2.529.

Norsworthy, J.K.; Ward, S.M.; Shaw, D.R.; Lewellyn, R.S.; Nichols, R.L.; Webster, T.M. Reducing the risks of herbicide resistance: best management practices and recommendations. Weed Science, v.60, n.1, p.31-62, 2012.

Oliveira Júnior, P.R.; Gualberto, R.; Rabello De Oliveira, P.S.; Costa, N.R.; Minotto Montans, F. Subdoses de herbicida e potássio em cobertura no sistema integração lavoura-pecuária. Pesquisa Agropecuária Tropical, v.40, n.3, p.242-250, 2010.

Silva, A.C.; Ferreira, L.R.; Silva, A.A.; Freitas, R.S.; Mauro, A. Épocas de emergência de Brachiaria brizantha no desenvolvimento da cultura da soja. Ciência Rural, v.35, n.4, p.365-367, 2005. http:// dx.doi.org/10.1590/S0103-84782005000400003.

Silva, P.I.B.; Fontes, D.R.; Moraes, H.M.F.; Gonçalves, V.A.; Silva, D.V.; Ferreira, L.R.; Felipe, R.S. Crescimento e rendimento do milho e da braquiária em sistema consorciado com diferentes manejos de plantas daninhas. Planta Daninha, v.32, n.2, p.301-309, 2014. http:// dx.doi.org/10.1590/S0100-83582014000200007.

Silva, U.R.; Timossi, P.C.; Almeida, D.P.; Lima, S.F. Eficácia do glyphosate na dessecação de espécies de Urochloa. Revista Brasileira de Herbicidas, v.12, n.2, p.202-209, 2013. http:// dx.doi.org/10.7824/rbh.v12i2.221.

Timossi, P.C.; Almeida, D.P.; Ramos, A.R.; Felisberto, P.A.C.; Lima, S.F.; Silva, U.R. Eficácia de glyphosate na dessecação de braquiárias em dois níveis de biomassa. Revista Brasileira de 
Herbicidas, v.1, n.4, p.313-322, 2016. http:// dx.doi.org/10.7824/rbh.v15i4.490.

Timossi, P.C.; Durigan, J.C.; Leite, G.J. Formação de palhada por braquiárias para adoção do sistema plantio direto. Bragantia, v.66, n.4, p.617-622, 2007. http://dx.doi.org/10.1590/ S0006-87052007000400012.
Zilli, J.E.; Smiderle, O.J.; Neves, M.C.P.; Rumjanek, N.G. População microbiana em solo cultivado com soja e tratado com diferentes herbicidas em área de cerrado no Estado de Roraima. Acta Amazonica, v.37, n.2, p.201212, 2007. http://dx.doi.org/10.1590/S004459672007000200005. 